\title{
Improving the Quality of Technology-Enhanced Learning for Computer Programming Courses
}

\author{
Aisha A. Othman, Crinela Pislaru, and Ahmed M. Impes
}

\begin{abstract}
Teaching computing courses is a major challenge for the majority of lecturers in Libyan higher learning institutions. These courses contain numerous abstract concepts that cannot be easily explained using traditional educational methods. This paper describes the rationale, design, development and implementation stages of an e-learning package (including multimedia resources such as simulations, animations, and videos) using the ASSURE model. This training package can be used by students before they attend practical computer lab sessions, preparing them by developing technical skills and applying concepts and theories presented in lecture through supplementary study and exercises.
\end{abstract}

Index Terms-Laboratory based learning, e-learning, ASSURE model, user-centered design.

\section{INTRODUCTION}

In the early 1990s, the Department of Computer Learning was established at the University of Omar Al-Mukhtar to provide a BSc degree in Software Engineering and Computer Science [1]. The course material is delivered through lectures (school-based learning, or SBL) and reinforced in the lab sessions (laboratory-based learning, or LBL). The SBL is based on a teacher-centered approach where experienced lecturers provide theoretical knowledge and information by using traditional facilities (e.g. blackboard and chalk) and the students receive printed lecture notes and read textbooks .Then the students attend LBL sessions in a computer lab based on a student-centered approach; the students have the opportunity to receive hands-on training for the techniques presented in the lectures by using the technologies and equipment existent in the computer labs. Recently, the academic staff has observed that students displayed a lack of practical experience and understanding of the theoretical subjects essential to the success of lab sessions Internal review reports show about a variety of issues concerning the learning processes and traditional teaching methods, limited access to IT, a lack of development processes, poor curriculum review, and a limited link between the practical tasks and theoretical content.

Due to large class sizes, especially at the undergraduate level, the vast majority of the Libyan higher education institutions face significant challenges in adequately assessing student learning and providing feedback to students Additionally, there are shortages of proper teaching facilities

Manuscript received June 18, 2013; revised September 13, 2013

The authors are with University of Huddersfield, UK (e-mail:roze_baida_2006@yahoo.com). and of science educators who are skilled enough to properly utilize course materials, practical exercises, and demonstrations. Some universities have opted to increase the number of faculty members, or to alleviate some of the strain by increasing the number of students who use one computer, but the majority of students still display a lack of practical experience and understanding of theoretical subjects during the computer lab sessions.

This paper describes the usage of a user-centered approach for the design, development, and implementation of an e-learning package (including multimedia resources such as simulations, animations, videos) and ASSURE model for the instructional planning process. ASSURE Model is an instructional guide for conducting and planning lessons that aim to integrate technology and media while focusing on the student's needs.

\section{THE ASSURE MODEL INSTRUCTIONAL PLAN}

Heinich et al. (1999) proposed the use of the ASSURE model for planning and delivering teaching sessions that integrate technology and media and for providing an authentic assessment of student learning [2]. "The ASSURE model allows for the possibility of incorporating out-of-class resources and technology into the course materials. This model will be especially helpful for instructors designing online courses."

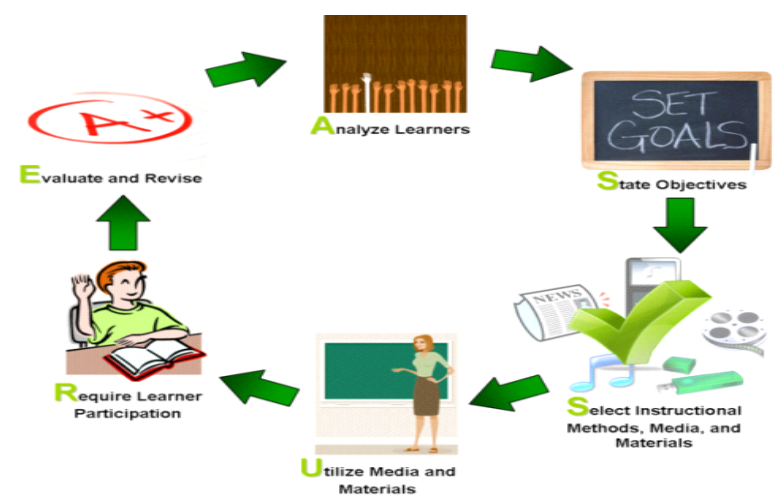

Fig. 1. The six steps of the ASSURE model.

This process or template for planning can help students make better usage of technology, in order to facilitate the learning process and the completion of further progress to achieve their goals. It provides opportunities to use digital tools instead of standard paper copy templates and evidence submitted by teachers. These digital tools can be accessed and stored anywhere with the proper connection (whereas papers may lost or left behind), and can improve cooperation between students [3]. A well-designed lesson attracts the 
attention of the learner, illustrating the goals to be achieved and providing new material. The student participates in practice, and the instructor assesses comprehension, delivers advice and is responsible for follow-up activities. It is a logical design and a simple guide for planning and implementing instructions that include media and technology. [4] Othman refers to these phases as "events of instruction."

\section{DEVELOPMENT OF AN E-LEARNING PACKAGE TO FACILITATE LBL IN COMPUTER PROGRAMMIG COURSES}

An instructional design model is a logical process to show how students learn and provide a guideline for the instructional stages of the learning process. Learning is facilitated when new knowledge is integrated in the life of the learner and linked to the real word. This is achieved by requiring the learner to display new knowledge, partake in new learned experiences, discuss new knowledge with peers and instructors, and use this new knowledge in practice. Hannifin said that new design ideas must evolve if we are to maximize the capabilities of new technologies for learning, yet we must not give up the accuracy provided by instructional design. This study will present two models that will be considered in terms of their suitability for use in the design of e-learning: the ASSURE model and User-Centered Design (UCD). These two models are illustrated in figures 1 and 2 below. Note that both models employ the five stages of ADDIE (analysis, design, development, implementation and evaluation), though not all in the same order or as separate steps in themselves.

\section{A. ASSURE Model}

The authors seek to increase the use of digital tools in computer programming courses, to help students organize information and visualize and understand the internal relations between the components of the scientific content. This can be achieved through cooperative educational activities, wherein students are divided into small electronic discussion groups to achieve common educational goals .[5] As the digital tools and multimedia promote individualized instruction, these can be employed to give students experience in a subjective manner on their own, with the teacher designing lessons centered on the student's individual characteristics using programmed learning such as modeling, simulation and role-playing games in extra-curricular educational activities [6]. The lessons are delivered by a qualified teacher using modern technological applications (a PowerPoint presentation, for example). The important lecture materials are available in an e-learning package provided by LBL course training.

Plan for $C$ programming language: The most important characteristic of this model is that it can be instituted by the instructor, without the need for instructional design specialists. The lesson plan focuses on instructing computer science students how to choose and use a range of digital tools. Students can determine the interests of the investigation, execute the investigation, and monitor progress towards the completion of their work. The following lesson plan for C programming follows the ASSURE model and ensures that the learning objectives use technology as a tool and not as a learning objective.

Analyze Learners: This lesson is developed for 50 students and delivered in two hour-long tutorials. All students would be enrolled in computing programming courses at Omar Al-Mukhtar University, most between 22 and 24 years old. Most students lack practical experience and understanding of theoretical subjects that are essential to the success of lab sessions. Students in this class also will have also taken a previous introductory class taught by the author during their third academic study year. By This time students have a clear understanding of the demands of their classes, are familiar with the classroom technology, and have advanced various basic skills in using those tools and technology .Actually there are findings have been done, "The findings showed that Libyan students had positive attitudes towards e-learning. The findings showed that e-learning supports traditional learning methods, the results based on the respondents' gender, educational level and age. The findings showed that E-learning is also an effective teaching method to motivate students to learn and encourage them to continue in further education. Thus, technology plays an important role in improving and developing teaching methods as well as giving students wider opportunities to learn".[7]

State Objectives: The instructor ensured that students knew the educational goals, which were divided into six stages (remembering, understanding, applying analyzing, evaluating, and creating). The instructor identified the needs of learners. This included determining how to utilize educational multimedia to advance the overall cognitive and emotional growth of the learners, and estimating the any shortages in technology.

Objective 1 - Remembering: Computer science students will be able to define the $\mathrm{C}$ programming theory and practical uses; they should know the process and activities for exercises; and they should recall basic elements of $\mathrm{C}$ programming learned in the SBL (e.g., they should be recall and understand the term "global variable," and they should be able to list 6 reserved words in C programming).

Objective 2 - Understanding: Students should be able to understand, explain, and describe the programming process. Students should be able to understand the issues (e.g. they should be able to describe idea of "software crisis," and they should able to find the value of $\mathrm{X}$ after running the $\mathrm{C}$ programming).

Objective 3 - Applying: Students should be able to apply appropriate fundamental principles for various activities and collect data for programming. They should be able to use plans, test plans, project plans and flow charts for software programs (e.g., they should be able to write a For Loop that can produce a desired result, and they should be able to write IF statement to display the average of some numbers).

Objective 4 - Analysis: Students should be able to solve problems using the basic commands of $\mathrm{C}$ programming, and should know how to use tools to solve command problems.

Objective 5 - Synthesis: The students should be able to build a program to solve a specific problem, to implement the activities leading to several programming languages, including codes, designs, requirements, and documentation.

Objective 6 - Evaluation: They should be capable of evaluating $\mathrm{C}$ programming language work for conformity to 
standards. They should know suitable quantitative and qualitative measures of application, and should be talented enough to practice those measures in the evaluation of software.

Select the Appropriate Method, Media, and Materials: The teacher chose suitable methods to deliver the necessary information, such as moving pictures or animation. This helped to engage learners' communication with the subject matter. For example, the teacher may organize the students into groups. One group may draw a flow chart for an exercise of $\mathrm{C}$ programming, and will present the idea to the other groups. A second group may take part in a simulation activity of $\mathrm{C}$ programming and discuss how to use the program step by step (perhaps using an online tutorial). Other students might work individually, using the Internet and various multimedia to carry out the editing and organization of the elements of code and writing scripts.

As appropriate, the instructor and students utilized a combination of the following materials:

Flip-chart: A group of students may utilize a flip-chart to present their ideas and explain the use of basic commands for running programming.

Computer: Individual students will use online tutorials and videos for solving problems.

Handouts: The lecturer will give to student handouts to help them focus more on their research for specific functions and commands.

Multimedia: Students will use multimedia tools on the e-learning package to discuss the issues and ideas as a group. The digital tools will allow the incorporation of sound into lessons, moving pictures, and animation, which gives students a more active role in the learning environment. They can watch practices in action, see small things up close, and use the keyboard or mouse to navigate interactive materials, simulations, and images. The use of multimedia helps to transfer information effectively and quickly to all students, and can keep students interested. The teacher can blend video, audio, text, simulations, images and multimedia into a single online environment via a Moodle application available to students from school or home.

Utilize Media, Materials, and Methods: It is more important to review and inspect each material before providing it to students; this stage can be used to pilot-test the lesson materials

Review the materials. Learners will be aware that the teacher needs to gather the tests, worksheets, and handouts distributed during the SBL.

Prepare the materials. The teacher will show students a visual display of the basic commands of the $\mathrm{C}$ programming by online tutorial or chart, and students can write notes during the explanation.

Prepare the environment. The lesson will be in two different places: in the classroom and in a lab.

The classroom setting (SBL) is arranged to encourage student participation. The tables are arranged for easy interaction in small group work. A Smart Board is connected to a computer and projected on a wall where all students can easily see it.

The laboratory based learning (LBL) provides students with access to computers that are connected to the Internet and on which are installed $\mathrm{C}$ programming and other required programs. Students can use the computer as a means to design research programs, print reports and activities, and can use the lab during leisure hours to gain additional practice. The computers can also facilitate team training and workshops in computer lab. Students receive practical experience learn teamwork with a set of software programs, they gain experience designing, implementing and testing programmable hardware and software which can use to do practical work, research, or homework.

Require Learner Participation: According to the singular learning strategy, it is key to integrate interactive activities into the learning process. Whether these activities are individual or collective, they contribute to meaningful learning and ensure the achievement of educational goals among a diverse class. Not all students will solve $\mathrm{C}$ programming; but by participating in interactive activities, they receive help to reinforce lessons learned in the classroom and are supported to become "detectives," to do more exercises in LBL sessions and get results and answers.[8]

Evaluate \& Revise: After each C programming lesson, students must answer questions to evaluate the objectives of ICT skills and student performance. The test is designed so that the number of correct and incorrect answers are displayed at the end of the test, and through review of these results, the teacher receives feedback on student performance and the acquisition of various skills.

\section{B. User-Centered Design (UCD)}

To operate correctly, user-centered design must be managed with the user in mind at every step of the process, as determined by the following four criteria.

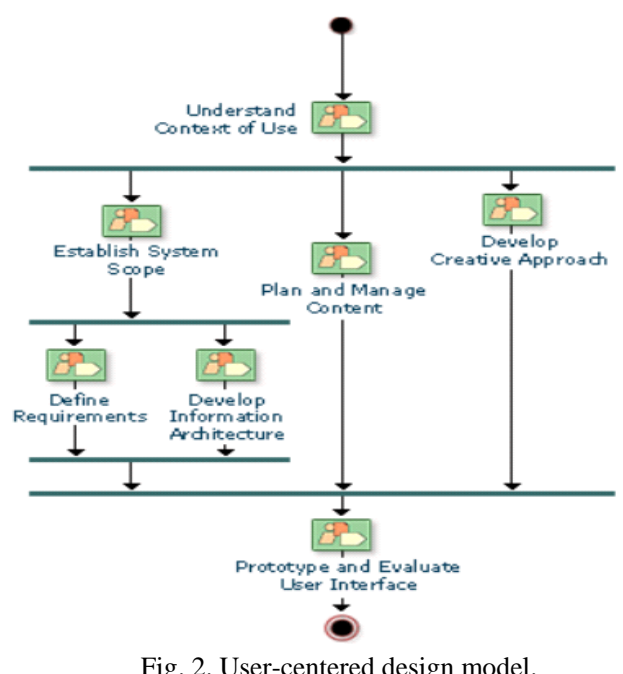

User analysis: It is key to understand the following about the users:

Mental specifications (e.g. willingness to learn, mental and developmental stages of language, reading level, learning strategies, language, culture, attention, orientation).

- Physical specifications (e.g. health and age).

Emotional specifications (e.g. hobbies, learning stimuli, students views toward the subject and their views about learning, the degree of fear and dread among students, self-confidence, discipline). 
- Social specifications.

- User needs.

Design. This is the stage for preparing a prototype, to describe how the e-learning package will work and look. It will contain a description of use and a designed model to best suit the goals of the users.

Prototype. This stage concerns the development and completion of an e-learning application that can be piloted.

Evaluation. The application must be reviewed by the designer and by other experts in the field of design for web-based learning and e-Learning. After the expert evaluation, the product can be evaluated by a test group (first a small number of individual students, and then a larger collective group of students) to identify necessary adjustments. Once adjustments are made, the product should be re-evaluated by another group [9].

\section{IMPLEMENTATION OF AN E-LEARNING PACKAGE TO FACILITATE LBL IN COMPUTER PROGRAMMING COURSES}

The ASSURE model illustrates the main steps to implement effective e-Learning. The model was developed to create a self-study product to be delivered by non-internet technologies (audio, video, paper-based, multimedia, etc.), but it has strengths that can be utilized in the design of e-Learning. Both the UCD and ASSURE models are appropriate and effective in the development of an e-learning package, and both are focused on the same instructional design issues: user analysis and design, content, structure, activities, evaluation, and feedback. As explained below, the model chosen does not matter as much as the options and decisions taken within steps of the model. In a computer programming course, practical work is the main method to provide skills to students. This requires that students attend the LBL to receive hands-on experience and work as a team while creating, designing, testing, and implementing projects hardware, software, and programming languages with a set of software programs, implementation, testing of programmable hardware, programming languages learned through the SBL sessions.

\section{A. Objectives of the e-Learning Package}

To provide opportunities for the needs of students that are not met in the LBL sessions, instructors should utilize new LBL course training materials. The students will take training sessions before they go to LBL sessions to resolve issues which faced them in the previous LBL. This will transform the course into a blended learning atmosphere: the information transfer will occur via the traditional SBL method, while the e-Learning package is applied for students' work collection, coursework presentation, e-material, and communication by way of the LBL module. The lessons are delivered by a qualified teacher and lecturer following the ASSURE lesson plan utilizing current technologies such as PowerPoint presentations and multimedia. The important lecture material will be available on the e-learning package provided by LBL course training.

\section{Design Features}

Based on the instructional design of the ASSURE and UCD models, the application will be created in such a way that will meet the requirements of all computer science students, regardless of their limitations on internet access. Consequently, a dual delivery status (ie CD-ROM based and e-Learning package) will be developed and implemented. While the LBL module can be used to interact simultaneously asynchronous and synchronous, the $\mathrm{CD}$ will include a self-learning materials multimedia. Features of the prototype include:

- Content development. The structure of computer programming course to be developed will include:

- Module 1: Website design

- Module 2: $\mathrm{C}++$ programming

- Module 3: Matlab

- Module 4: Java

- Module 5: Database

- Courseware development. The content and sources are developed in such a way that many features are available through a range of software programs that can be used with all of the e-learning package and interactive CD-ROMs..

- Content delivery. The key elements to provide content for the proposed computer programming course are:

- Multimedia components will be on CD only. The purpose of this is to help the student understand the step-by-step lesson without the risk of a slow Internet connection, and to provide self-learning materials through PowerPoint slides and e-tutorial to supplement the text before going to the lab.

- Feedback with self-evaluation (both on e-learning package and CD). This will consist of self-evaluation and continuous assessment for all modules in the form of learning practical tasks, short answer questions, quizzes, and a questionnaire to assess the modules. All of these are part of the educational curriculum.

- An interactive learning forum will be provided in the prototype via email, blog, wiki, and discussion board.[10]

\section{B. Choice of Platform}

The package is being developed entirely as an e-learning platform on two levels:

1) The front end of the engine program includes lecture material in text, charts, and slide shows related to evaluation and interaction, staff information, tutorial materials (e-tutorials, activities, pictures, and videos), students resources, and announcement. The following elements will be encrypted: training modules, self-assessments, self-evaluations, and time evaluations (for time spent on all modules combined, each module individually, other activities, and the final project).

2) The CD version will download with multimedia elements while the Internet can be used to interact either synchronously and asynchronously. The particular application tools for the training module are established with a full Learning Management System (LMS), including chat capabilities, discussion forums, and e-mail. The same tools can be used in the future to deliver any other necessary training programs.

\section{Learning Time}

Each module should take students between 5 and 10 hours per week. This time will be divided between reading, slide shows/e-lessons, hands on practice, and self-assessment. 


\section{Prototype Development}

This stage considers two elements at two simultaneous and parallel levels: the courseware (i.e. the core of the electronic educational content) and the delivery software. The development of the package has been envisaged in the following sub-stages:

- Pre-evaluation: Experts in computer programming and e-learning will be invited to evaluate the training curriculum and the interface of the e-learning package. The researcher will consider the suggestions of the experts about design e-learning package and the courseware.

- Courseware Development: This includes the development of educational curricula such as slides, animation and other multimedia components. The slides and content of all modules are now ready. Development of required videos and e-tutorial are in progress.

- Software Development: The researcher has been developing a complete e-learning solution based on users' requirements. The text content is integrated with the application. Integration of the electronic modules is in progress. After integration, the e-learning package of the training program is to be hosted on the network, and a small number of CDs will be made to test the prototype.

- Prototype Testing: A workshop with various academic staff will be organized to test the prototype.

- Prototype Evaluation: The main parameters for evaluating the prototype are content, interface design, technical functionality, timing, and interaction.

- Population of evaluation: The LMS experts, the computing department academic staff and students.

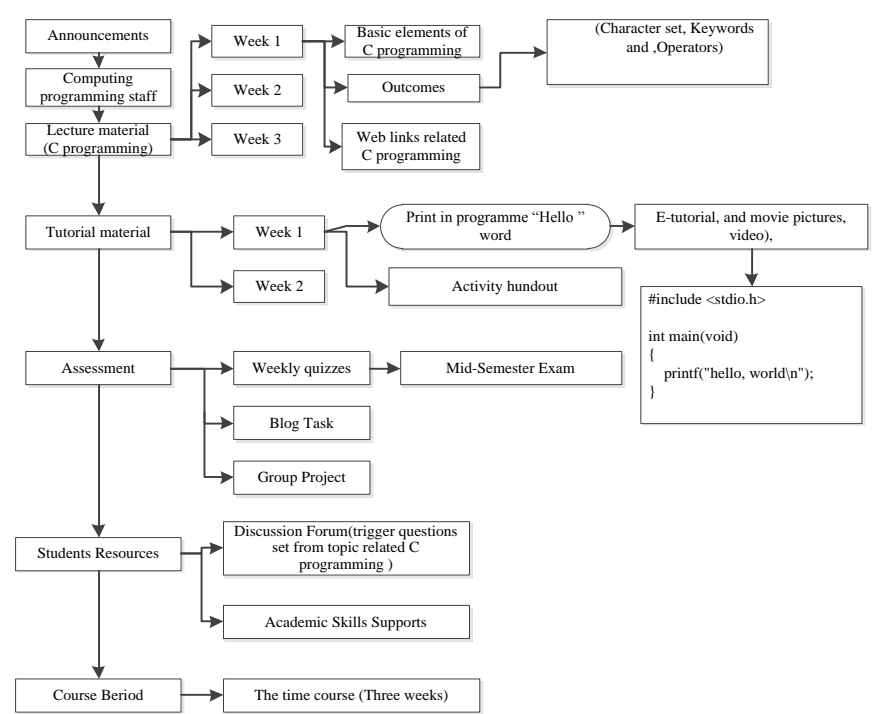

Fig. 3. Example of course site organization for the $\mathrm{C}$ programming module.

Methodology for evaluation: An effective feedback form will be implemented to evaluate the above aspects. The feedback will be collected via questionnaire and online test. The package will be implemented based on the evaluation received from the workshops of the prototype testing. Any necessary corrections and amendments will be made, and multiple CDs will be made and distributed for further implementation.

Delivery of the Computer Programming Course: The program will start after a registration process. The duration of the implementation of the program will be three weeks. It is scheduled in live online chat sessions with international and national experts from Omar Al-Mukhtar University, where students can react immediately with them. The program will be piloted on a small number of individual students, then on a group of students to simulate collective work. Any necessary adjustments will be made, and a final testing program will be conducted. Based on the evaluation from students, future applications will be considered.

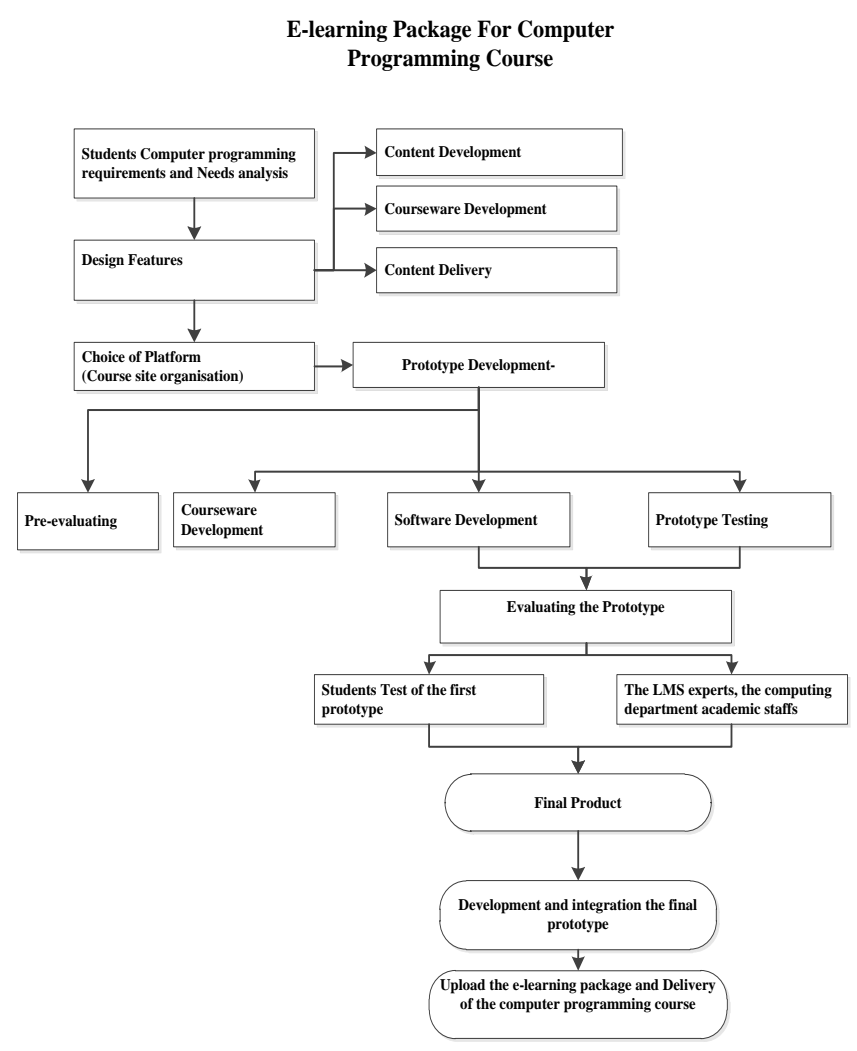

Fig. 4. User-centered design stages For e-learning package.

\section{CONCLUSIONS}

This study has shown that the use of computer animations can assist students to better understand complex and difficult concepts in various computer courses. The LBL course training will allow the incorporation of sound, moving pictures, and animation into lessons, which extends instructors' capabilities to deliver materials that increase learners' interaction with the subject matter. Through these media, students can watch practices in action, see micro-views of larger structures, and navigate interactive materials, simulations and images. E-tutorials will take place of the computer programming teachers in a virtual state. This will offer step-by-step directed tours of the entire e-learning package. Multimedia can transfer information effectively and quickly to all students, and can keep students interested in SBL. The researcher will blend video, audio, text, simulations, images and multimedia into a single online Moodle application available to students at school or home. The e-Learning package will help learners to improve research and technical skills, which cannot be accomplished by reading a textbook in the SBL or LBL workplace. The links will be on the Moodle application, which will help students use online resources by offering news archives, databases for online libraries, and a wealth of other 
information. Also, an LBL module can train educators to provide materials to students more clearly anytime and anywhere.

\section{REFERENCES}

[1] Omar Al-Mukhtar University, Computer Science Department homepage, 2013.

[2] R. Heinich, M. Molenda, J. Russell, and S. Smaldino, Instructional media and technologies for learning, 6th ed., Upper Saddle River, NJ: Prince Hall, 1999.

[3] S. E. Smaldino, D. L. Lowther, and J. D. Russell, Instructional technology and media for learning, Upper Saddle River, NJ: Pearson Education, 2008.

[4] A. Othman, C. Pislaru, and A. Impes, "Improving Students' ICT Skills By Using A Novel Framework For A Lab-Based Learning Module," in Proc. the Fourth International Conference on e-Learning (ICEL2013), Ostrava, Czech Republic, pp. 106-113, 2013.

[5] R. Pimmel. (2001). Cooperative learning instructional activities in a capstone design course,American Society for Engineering Education. [Online].

available: http://www.encyclopedia.com/doc/1P3-81919737.html

[6] M. R.Young, B. R. Klemz, and J. W. Murphy, "Enhancing Learning Outcomes:The Effects of Instructional Technology, Learning Styles, Instructional Methods, and Student Behavior," Journal of Marketing Education, vol. 25, no. 2, pp. 130-142, DOI: $10.1177 / 0273475303254004,2003$.
[7] A. Othman, C. Pislaru, and A. Impes, "Attitudes of Libyan students towards ICT's application and e-learning in the UK," in Proc. the Fourth International Conference on e-Learning (ICEL2013), Ostrava, Czech Republic, pp. 123-129, ISBN: 978-0-9853483-9-7, 2013.

[8] A. Othman, C. Pislaru, and A. Impes, "Online Interactive Module for Teaching a Computer Programming Course," in Proc. the 12th European Conference on e-Learning ECEL-2013, 2013.

[9] A. Othman, Investigating an On-line Teaching and Learning Environment for the University of Omar Al-Mukhtar, Libya, MSc Thesis. In: UK, University of Huddersfield, 2010.

[10] A. Othman, C. Pislaru, and A. Impes, "Determination of generic skills gap between school-based learning and laboratory-based learning in Omar Al-Mukhtar University," in Proc. the International Conference on Electrical, Computer, Electronics and Communication Engineering FR, Paris, 2013.

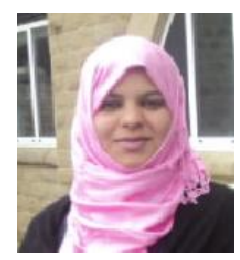

Aisha Abdraba Othman is a $\mathrm{PhD}$ candidate in the School of Computing and Engineering at the University of Huddersfield, UK. She has studied at University of Omer AL-mukhtar, Libya and then obtained the MSc degree in Information System Management at the University of Huddersfield, UK. Her research is focused on methods of combining traditional learning and e-learning; intelligent e-learning technology; interactive e-learning systems; E-learning multimedia applications and pedagogical challenges; new trends in learning and training; impact of e-learning on social change; developing an organizational strategy for e-learning; evaluation methods in blended learning environments and intelligent user interfaces. 